Partial Gastreotomy.

If the growth be limited to the body of the stomach, partial gastrectomy may be done by a free circular or elliptical incision, the opening being closed by a continuous chromicised gut suture to the mucous margin and interrupted Lembert sutures to the peritoneal coat, all bleeding points being previously caught up and ligatured.

In many cases, both of sarcoma and cancer, the disease has advanced well into the body of the stomach, and to get it away an extensive partial gastrectomy has to be performed. In Langenbuch's case in 1894 he excised seven-eighths of the stomach, and sutured the pylorus to the small cardiac portion of stomach remaining, the patient making a good recovery. This operation has been repeated a number of times by others, and with considerable success. A list of collected cases of almost complete gastrectomy, in which at least threefourths of the stomach has been removed for cancer, contains 14 cases with 4 deaths, equal 28.5 per cent. mortality. My colleague Mr. Ward has done three partial gastrectomies; two cases succumbed to the operation, but the first patient doubled her weight in three months.

It seems advisable in these cases to close the gastric openings, and establish a gastro-enterostomy with the remaining portion of the stomach, but the technique will depend on the amount of stomach removed and the state of the parts left.

In concluding my appointed task as Hunterian Professor, I venture to hope that I have succeeded in demonstrating what an important relation surgery bears to diseases of the stomach, both simple and malignant. I have tried to prove my points not only by the relation of some of my own cases, but by statistical evidence gathered from all sources, and, in the latter, my work has been lightened by the kind assistance of Mr. Willmott Evans. I know how wearisome to the average reader is the study of tables of statistics, but I venture to think that they will show not only the actual riek of any special operation, but also how greac is the improvement that is taking place in the results of stomach operations generally.

I am proud to be able to say that my last 32 operations on the stomach in my private practice have all reoovered, and I can see no reason why the success in this branch of surgery should not be as great as in gall-bladder surgery, which now holds a very different position to what it did when I gave my first pap'r on the subject before the Clinical Society in 1885 , nay, even to what it did when I lectured from this chair on Diseases of the Gall Bladder and Bile Ducts in 1897. In order, however, that surgery may attain its maximum amount of success, we must ask our medical colleagues for earlier diagnoses and earlier surgical consultations so that if the case is one that can be only cured or relieved by an operation, it may be performed before the recuperative powers have been lost. Then, and only then, shall we attain the ideal.

$$
1 \text { Arch. f. klin. Chir, 1896, vol. li, p. } 484 .
$$

CORRECTION.

TREATMENT OF GASTRIC ULCER.

Mr. Mayo Robson points out that in the synopsis of his first lecture, published in the BRITISH MEDICA: JoURNAL for March roth, rgoo, p. 564 , there is a printer's error, which, if allowed to pass, would give a wrong impression of the mortality in operations on intractable ulcers of the impression of the mortality in operations on intractable ulcers of the should read. "I find that I have operated on 34 cases of intractable gastric ulcer, with various complications, which in every case must have caused permanent disability, or would have ended fatally, but excluding perforation, hæmorrhage, and cancer, all of which I am considering separately. Of these, 18 operations were done in private with one death, giving a tality of $3 \tau^{2} 2$ per cent.; or, if both private and hospital cases be taken together, the mortality is 17.6 per cent.

Medical Graddates in Gramany.-The total number of degrees in medicine conferred by the German universities in the academic year 1898.99 was 1,050 . Of these, Berlin gave 87, Bonn 22, Breslau 30, Erlangen 47, Freiburg-in-Baden 6o, Giessen 32, Göttingen 31, Greifswald ro, Halle 23, Heidelberg 32, Jena 34, Kiel 86, Königsberg 24, Leipzig 55, Marburg 28, Munich 134, Rostock. 14, Strassburg 43, Tübingen 46, and Würburg 147. The number of degrees awarded by these universities in the previous academic year was 1,208 , while the corresponding figure for $18,96-97$ was 1,268 , showing a progressive diminution.

\section{A NEW METHOD OF PERFORMING PERINEAL PROSTATECTOMY.}

BY P. 'J. FREYER, M.A., M.D., M.СH., Surgeon to St. Peter's Hospital.

Tre vast majority of cases of senile enlargement of the prostate are, in my opinion, best treated by careful, cleanly, and judicious catheterism. There is, however, a minority in which a surgical operation of some kind is advisable, and a 'still smaller proportion in which an operation is imperative to save the patient's life or ameliorate his sufferings. I propose this evening introducing to your notice, by means of an illustrative case from practice, a new method of removing certain forms of enlarged prostate through the perineum. In order to clear the wav for your appreciation of this procedure, I shall classify briefly the various recognised surgical operations for the disease under consideration as follows:

I. Palliative operations, undertaken when there is cystitis or some other complication present, rendering catheterism impossible or extremely difficult.

(1) Suprapubic cystotomy, with temporary or permanent drainage through a retained tube.

(2) Perineal urethrotomy, with temporary or [permanent drainage.

2. Operations undertaken for the purpose of inducing permament atrophy or shrinkage of the prostate.

(1) Castration.

(2) Vasectomy.

3. Radical operations, which aim at removing a part or the whole of the obstructing portion of the gland:

(1) Division of a median obstruction by means of the galvanocautery introduced through the urethra (Bottini) or through a perineal urethrotomy (Wishard).

(2) Removal of a median growth through a perineal opening in the urethra by cutting forceps or other instrument.

(3) Suprapubic prostatectomy (McGill), suitable only for enlarged middle lobe, ring of hy pertrophied tissue round the orifice of the urethra, or enlargements of the lateral lobes projecting into the bladder.

(4) Perineal prostatectomy by Dittel's method, which consists in removing a wedge-shaped portion from the under surface of one or both lateral lobes, through an incision extending from the median raphe round the sphincter ani to the tip of the coccyx, the urethra and bladder being left intact.

(5) Nicoll's operation, which is similar to this last, only that a preliminary suprapubic cystotomy is performed, for the purpose of introducing a finger into the bladder, with a view to pushing the prostatic tumour into the perineal wound, thus facilitating its removal.

In the operation that I am about to describe advantage is taken of the perineal incision recommended by Dittel, but Nicoll's object is attained by a much less heroic and dangerous proceeding than suprapubic cystotomy-namely, by a preliminary perineal opening into the urethra.

A gentleman aged 59, sent by Dr. Richard Heath, of St. Leonards. onSea. consulted me on October Irth, r889, suffering from the following

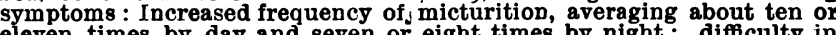
eleven times by day and sevep or eight times by night; diffculty in starting the stream, necessitating much straining to effect this; he find the abdomen upwards the stream starts mof readily. Diminished force of is intermittent. The urine is clear, as a role; some eight months ago it was very dark in colour, but patient cannot say if it contained blood. Pain and discomfort behind the glans during micturition, and discomfort above the pubes before the act. The symptoms have existed three years. and have been gradually growing worse. At first they were more years. and have been gradualat growing worse. At frst in the daytime. They are increased by exercise, particularly in walking.

Theore increased by exercise, particularly in walking. culty in passing the instrument over the enlarged prostate. Residual culty in passing the instrument over the enlarged prostate. Residual
urine, $4^{\frac{1}{2}}$ ounces; trace of albumen. Per rectum there was a tumour felt urine, 43 ounces; trace of albumen. Per rectum there was a tumour ele in the right side of the prostate, twice the size of a walnut, very dense on pressure. This nodule felt like a stone embedded in the prostate. The on pressure. This nodule felt like a stone embedded in the p
left lobe of the prostate was scarcely enlarged. and quite soft.

On the 17th I made a cystoscopic examination, the patient being anæsthetised by Dr. Dudley Buxton, and Mr. Victor Horsley being present in consultation. The right lobe of the prostate was seen to be enlarged and projecting into the bladder, the size of a walnut, irregularly nodulated, and of a dark brown colour. The left lobe was not visible in the bladder. which, generally, presented a healthy appearance, except that the mucous membrane was trabeculated, the result of constant straining and back- 
ward pressure of urine. After consultation exploration of the bladder by a perineal urethrotomy was decided on, and this was carried out next day. The urethra was opened in front of the prostate on a staff. On passing my finger through the opening I found a round, prominent mass, involving the right lobe of the prostate, projecting into the bladder, but no stone could be detected. On inserting the forefinger of my other hand into tine rectum, the hard nodule was felt as before, and the tumour clearly defned, rounded and intensely hard, the left lobe of the prostate being almost normal. After consultation with Mr. Horsley, we determined to remove the tumour perineally. A crescentic incision about 4 inches long was made from the median raphe at the lower end of the urethral wout, back side. Tho disection was roctum was passed hrough tho urethral wound into the bladdor and hooked woll into view. The capuls of the prostate was incised and peeled by means of an elevator. The tumour, which involved the whole of the by means of an olovat. The ture of the right lobe of tho prostate, was thus removed piecemeal by cutting forcep and curved scissors, only a thin layer being left to support the mucous membrane of the bladder and prostatic urethra, which was left intact no vessels being ligatured. On completion of the operation a solt-rubber no vessels being ligatured. and retained there by a suture, and on this a rubber drainage tube was fixed to convey the urine to a vessel beneath the bed. The large gaping wound in the ischio-rectal fossa was packed with iodoform gauze and the usual dressings applied.

The perineal tube was kept in for six days, during which time the whole of the urine passed through it, not a drop escaping beside the tube, thus obviating any chance of infection of the deep ischio-recta wound till it had partly flled up and was covered by healthy granu-
lations. The temperature rose to roo $\mathrm{F}$. on one night, after which it did not go above $99^{\circ} \mathrm{F}$

After a fortaight the urine began to pass partly through the urethra, and after a few days later no urine passed by the perineal wound in the urethra. The patient was sitting up on December rst. On the s8th he
left the surgical home, untroubled by any urinary symptom, and he is now quite well.

The tumour turned out to be of the fibro-adenomatous type, frequently met with in the prostates of the aged, the fibrous elements predominating. It was as hard as scirrhus. About its centre a few drops of pus were found in the middle of a small coagulum, due to a thrombus or irritatio of a small prostatic concretion found in this vicinity.

The advantages claimed for this method of operating are :

1. The preliminary external urethrotomy permits of the introduction of the finger into the bladder, which, with finger in the rectum, enables the surgeon to define accurately the shape, density, size, and extent of the prostatic growth in a manner that cannot otherwise be accomplished, except, perhaps, by a suprapubic opening - a much more serious proceeding.

2. The finger can be hooked over the enlarged lateral lobe and the latter pushed well into the ischio-rectal wound, thus to a large extent obviating a deep and dangerous dissection, as in Dittel's operation.

3. With the tumour pushed well into the wound the capsule is easily incised and erased, and the cutting forceps and scissors easily and freely applied, to eradicate the whole mass.

4. The finger in the bladder enables the surgeon to feel when the cutting instruments are approaching that viscus, so that he can remove the whole growth, except a thin layer for the support of the mucous membrane of the bladder and prostatic urethra, withont opening the latter, thus avoiding infection of the wound and the existence of a permanent fistula.

5. The stout perineal drainage tube inserted into the urethral wound carries off all the urine and prevents the perineal wound from becoming septic.

The drawback to the operation is that, like all other operations proposed for the removal of prostatic growths, it is applicable only to certain forms of the disease. It is not, of course, applicable to cases of enlarged middle lobe projecting into the cavity of the bladder. For such cases McGill's operation is undoubtedly the best. In very fat patients, or when the prostatic tumour is extremely large, it may not be feasible, owing to the fact that the finger may not in such cases be sufficiently long to hook it round the growth.

Presefantation.-On March 2oth, Dr. Major Greenwood, Honcrary Secretary of the Brussels Medical Graduates' Association, was presented by Dr. Danford Thomas, in the name of the members of the Association, with a handsome gold watch and chain, and a silver cigarette case. The watch has the following inscription: "Presented to Dr. Major Greenwood by members of the B.M.G.A. as a token of their high regard and a slight recognition of valuable services as Honorary Secretary, March, 1900."

\section{MEM ORANDA:}

MEDICAL, SURGICAL, OBSTETRICAL, THERAPEUTICAL, PATHOLOGICAL, ETc.

\section{WHEN IS CANCER CURED?}

With regard to this important question, which Mr. Jalland asks in the British Medical Journal of February 17 th, the following case is full of interest.

The patient is aged 7o years. Twenty-five years ago the left breast was removed for mammary cancer. For fifteen years she remained free from the disease, but after the period of immunity a recurrence took place high up in the axilla, which fungated and then contracted, and there is now a puckered ulcerating cicatrix.

Five years ago, a mass appeared in the middle of the posterior surface of the upper arm; this fungated one year ago, and has bled frequently, but only once sufficiently to canse any anxiety. There are also many other secondary growths in the arm in the subcutaneous tissue, and some have ulcerated. There are also multiple nodules in the skin. The arm is enormously swollen, and there is much pain; the patient has lost ground rapidly since I first saw her in September, 1899.

The operation was performed twenty-five years ago by the most eminent surgeon of the day, and he stated that if recurrence did not take place for ten years the patient would remain free of the disease. Such, I suppose, represented the opinion of the day. Since the more radical operations on the mamma for cancer have been introduced, surgeons have naturally looked for better results, and the tendency has been in some quarters to speak of definite "cures" after operation, and to assert that after three years have passed all danger of recurrence is at an end.

Four years ago Mr. Watson Cheyne brought forward 22 cases operated upon by the more radical method, and at that time 13 of these cases were alive and free from recurrence, and more than three years had elapsed after the operation, these cases having passed the "time limit" were spoken of as "cures." The life-history of these 13 patients now or in a few years would be most interesting and important.

Two years ago, at a long debate at the Royal Medical and Chirurgical Society upon a paper by Mr. Marmaduke Sheild on Immunity and Latency after Operations for Cancer of the Breast, the general tendency was not to speak of freedom from the disease for a fixed number of years as a "cure." This seems to be the correct view to take, and in the present state of the pathology of cancer the answer to the question cannot be given definitely with perfect candour and honesty.

The case related above is interesting as showing the extraordinary latency exhibited, and it also demonstrates how enormously the rate of growth of mammary cancer varies. The immunity existed for fifteen years and recurrence took place ten years ago, and yet the patient is still living.

Salisbury.

E. T. Fison, M.D.Cantab., F.R.C.S.Ed.

KERNIG'S SYMPTOM IN MENINGITIS.

In the British Medical Jodrnal of February 3 rd, Major Buchanan refers to Kernig's symptom in meningitis, and describes a similar condition occurring in the upper extremities. In conclusion he says: "I have not been able to find any allusion to this symptom appearing in the arms in any of the numerous writings on this disease that I have been able to come across."

I wish now to point out that this is no new observation. During the last ten or twelve years I have frequently demonstrated under the term " over-action of the flexors" the so-called Kernig's sign occurring in the lower extremities, and a similar condition in the upper. In a lecture of mine on the Treatment of Typhoid Fever, in the Lancet of March 15th, 1890, the following sentences occurred in describing a case complicated with meningitis :

Her head is still very much retracted, the muscles of the upper limbs rigid, and the flexors are so much contracted that the forearms are acutely flexed on the arms: the thumbs are adducted to the centre of the palms, and the fingers are flexed. The lower limbs are drawn up, the thighs flexed on the abdomen, and the legs on the thighs, and the feet are extended. Ankle clonus and patellar
refiex still marked, plantar reflex increased, but the other superficial refex stil marked, plantar reflex
reflexes are barely, if at all, elicited. 